\title{
Utilizing a Single Silica Nanospring as an Insulating Support to Characterize the Electrical Transport and Morphology of Nanocrystalline Graphite
}

\author{
Peter M. Wojcik ${ }^{1}$, Negar Rajabi ${ }^{1}$, Haoyu Zhu ${ }^{2}{ }^{\oplus}$, David Estrada ${ }^{3,4}$, Paul H. Davis ${ }^{3}{ }^{(0,}$ \\ Twinkle Pandhi ${ }^{3}$, I. Francis Cheng ${ }^{2}$ and David N. McIlroy ${ }^{5, *}$ \\ 1 Department of Physics, University of Idaho, Moscow, ID 83844, USA; petewojcik@gmail.com (P.M.W.); \\ pasargad23@gmail.com (N.R.) \\ 2 Department of Chemistry, University of Idaho, Moscow, ID 83844, USA; \\ zhu1099@vandals.uidaho.edu (H.Z.); ifcheng@uidaho.edu (I.F.C.) \\ 3 Micron School of Materials Science and Engineering, Boise State University, Boise, ID 83725, USA; \\ daveestrada@boisestate.edu (D.E.); pauldavis2@boisestate.edu (P.H.D.); \\ twinklepandhi@u.boisestate.edu (T.P.) \\ 4 Center for Advanced Energy Studies, Boise State University, Boise, ID 83706, USA \\ 5 Department of Physics, Oklahoma State University, Stillwater, OK 74074, USA \\ * Correspondence: dave.mcilroy@okstate.edu
}

Received: 18 October 2019; Accepted: 14 November 2019; Published: 19 November 2019

\begin{abstract}
A graphitic carbon, referred to as graphite from the University of Idaho thermolyzed asphalt reaction (GUITAR), was coated in silica nanosprings and silicon substrates via the pyrolysis of commercial roofing tar at $800{ }^{\circ} \mathrm{C}$ in an inert atmosphere. Scanning electron microscopy and transmission electron microscopy images indicate that GUITAR is an agglomeration of carbon nanospheres formed by the accretion of graphitic flakes into a $100 \mathrm{~nm}$ layer. Raman spectroscopic analyses, in conjunction with scanning electron microscopy and transmission electron microscopy, indicate that GUITAR has a nanocrystalline structure consisting of $\sim 1-5 \mathrm{~nm}$ graphitic flakes interconnected by amorphous $\mathrm{sp}^{3}$ bonded carbon. The electrical resistivities of 11 single GUITAR-coated nanospring devices were measured over a temperature range of $10-80^{\circ} \mathrm{C}$. The average resistivity of all 11 devices at $20^{\circ} \mathrm{C}$ was $4.3 \pm 1.3 \times 10^{-3} \Omega \mathrm{m}$. The GUITAR coated nanospring devices exhibited an average negative temperature coefficient of resistivity at $20^{\circ} \mathrm{C}$ of $-0.0017 \pm 0.00044^{\circ} \mathrm{C}^{-1}$, which is consistent with the properties of nanocrystalline graphite.
\end{abstract}

Keywords: nanocrystalline graphite; nanosprings; nanocoils; nanowires; TCOR (temperature coefficient of resistivity); Raman spectroscopy; SEM (scanning electron microscopy); TEM (transmission electron microscopy)

\section{Introduction}

The carbon material dubbed graphite from the University of Idaho thermolyzed asphalt reaction (GUITAR) was first observed as the carbonaceous residue from the combustion of oil shale. Previous scanning electron microscopy (SEM) and optical images of GUITAR are consistent with a typical graphitic material [1]. X-ray photoelectron spectra indicate that the $C$ bonding in GUITAR is a combination of $\mathrm{sp}^{2}$ and $\mathrm{sp}^{3}$ hybridized carbon [1], further supporting the conclusion that it is a form of graphite. However, GUITAR exhibits unique electrochemical properties that deviate from those of typical graphitic materials. The basal plane of GUITAR has fast, heterogeneous electron transfer kinetics and outperforms graphene, graphites, carbon nanotubes, boron-doped diamond, and diamond-like carbon $[2,3]$. The aqueous anodic and cathodic limits notably exceed those of other graphitic carbons, 
which results in better corrosion resistance relative to other graphitic materials [2,4]. These features make GUITAR an excellent candidate for use in applications such as sensors [5], energy storage and conversion [6], and water purification [3].

The unique electrochemical properties of GUITAR suggest that it is not just another form of graphite; further investigation of its morphology and electrical properties is required to classify GUITAR within the spectrum of carbon materials. The electrical resistivity and the temperature dependence on the resistivity of carbon nanocoils (NCs), graphite, and other allotropes of carbon vary greatly from allotrope to allotrope [7-19], thereby assisting in their identification and classification. The Raman spectra of the different carbon allotropes is equally diverse [20-28]. When taken in conjunction with one another, the electrical characterization and the Raman spectroscopy of GUITAR should be sufficient to identify and classify it within the spectrum of carbon allotropes.

Herein, we report on a unique approach to producing a better understanding of the morphology and electrical properties of GUITAR. GUITAR was coated onto silica nanosprings (NSs), which served as an insulating support. Then, a single GUITAR-coated NS (G-NS) device was constructed to determine the electrical properties of GUITAR. The use of silica NSs allowed us to precisely characterize the morphology of GUITAR and correlate it with its electrical properties. While this approach is not well-suited to single crystal materials, it is ideal for characterizing the electrical properties of amorphous and polycrystalline materials such as GUITAR.

\section{Experimental}

\subsection{Silica NS Growth and GUITAR Deposition}

Silica NSs were grown in bulk on silicon substrates using a method previously described by Wojcik et al. [29] and Wang et al. [30]. GUITAR was deposited onto the silica NS surface via the pyrolysis of commercial roofing tar (asphalt) in a tube furnace operating at $800^{\circ} \mathrm{C}$ under a continuous flow of nitrogen. The deposition of GUITAR has been previously described in detail $[1,4,31]$. This process was modified slightly in order to deposit a thin $\sim 100 \mathrm{~nm}$ coating on the NS surface. Five grams of asphalt were wrapped in an alumina blanket and placed in the center of a hollow, 10 inch long by 3 inch diameter, steel cylindrical tube (Figure 1a-c). The silicon substrate with bulk silica NSs was placed above the alumina blanket and the steel cylinder was placed in the center of a tube furnace. The furnace was ramped to $800{ }^{\circ} \mathrm{C}$ in 15 min while flowing $\mathrm{N}_{2}$, then cooled slowly over five hours until the furnace temperature reached $\sim 50^{\circ} \mathrm{C}$, at which point the sample was removed.
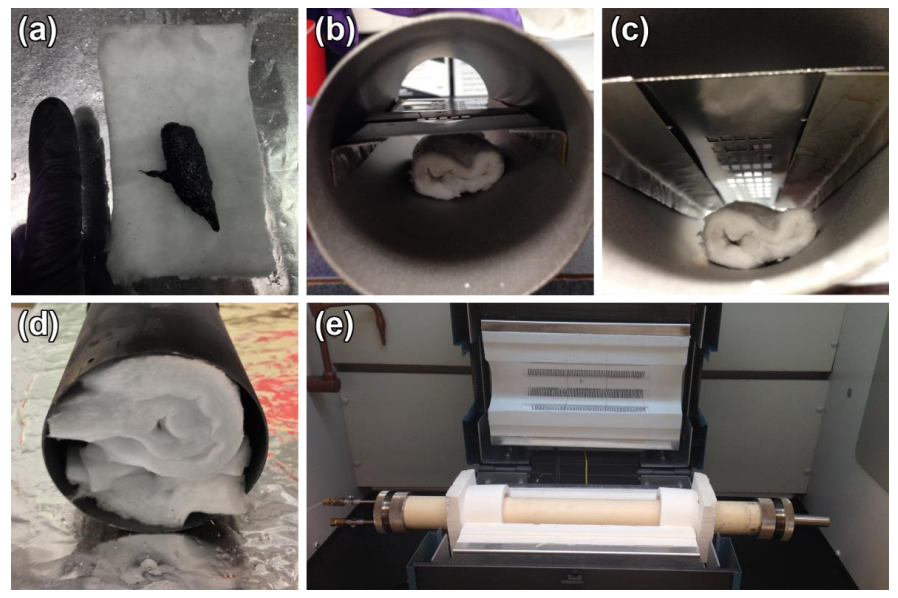

Figure 1. Graphite from the University of Idaho thermolyzed asphalt reaction (GUITAR) deposition experimental setup. (a) Five grams of asphalt on an alumina blanket; (b) alumina blanket with asphalt placed below a NS sample inside a cylindrical steel tube; (c) NS-coated surface faces down toward an alumina blanket; (d) endcaps of the cylindrical steel tube capped with the alumina blanket; (e) tube furnace with the $\mathrm{N}_{2}$ inlet on the left and open exhaust on the right. 


\subsection{Device Fabrication}

A drop-casting method was used to deposit the G-NS on a silicon substrate with a $500 \mathrm{~nm}$ thick thermal oxide $\left(\mathrm{SiO}_{2} / \mathrm{Si}\right)$. The G-NS/isopropanol (IPA) suspension was obtained by submerging the G-NS coated silicon substrate in a beaker of IPA and vigorously agitating with a pipette, thereby releasing the G-NSs into solution (Figure 2a). Prior to drop-casting, the $\mathrm{SiO}_{2} / \mathrm{Si}$ substrates were cleaned by sequential soaking in acetone, IPA, and deionized water, followed by drying with $\mathrm{N}_{2}$. The G-NS/IPA solution was drop-cast onto the clean $\mathrm{SiO}_{2} / \mathrm{Si}$ and the IPA was allowed to evaporate (Figure $2 \mathrm{~b}$ ). This procedure was repeated until the desired amount of G-NSs were deposited on the $\mathrm{SiO}_{2} / \mathrm{Si}$ substrate. Following drop-casting, a lithographic pattern of a series of interdigitated electrodes was produced on the $\mathrm{SiO}_{2} / \mathrm{Si}$ substrate by a standard bilayer photolithography process using LOR3A (lift-off resist) and SPR220-4.5 photoresist. Both resists were manufactured by MicroChem Corporation. The LOR3A provided an undercut layer beneath the SPR220-4.5, which facilitated the removal of the photoresist during the lift-off process. The electrical contacts consisted of sequential layers of Ti $(20 \mathrm{~nm})$ and $\mathrm{Au}(200 \mathrm{~nm})$ deposited by thermal evaporation. A Model 110 micromanipulator with a Model 7A probe tip (The Micromanipulator Co., Carson City, NV, USA) and an optical microscope were used to selectively remove the G-NSs along the electrode gap until one G-NS remained. Chips were fabricated with 27 interdigitated electrodes. Each electrode had a $\sim 12,000 \mu \mathrm{m}$ long channel to increase the probability of making Ohmic contact with a single G-NS. The yield for this design process was $\sim 5$ active devices per chip.

(a)

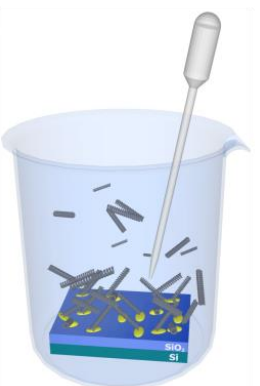

(c)

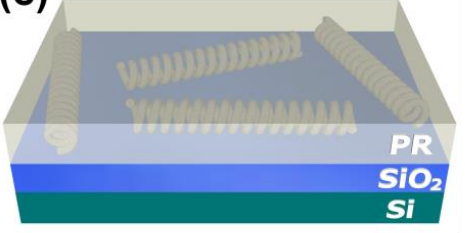

(f)

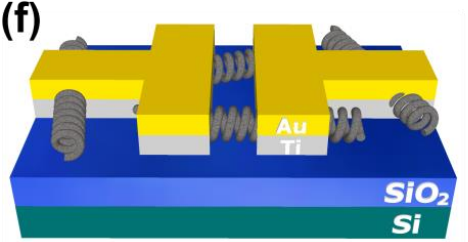

(b)

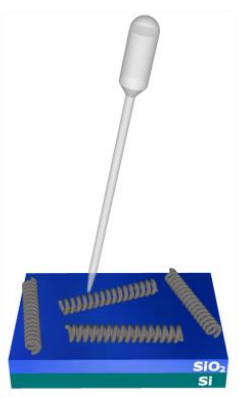

(e)

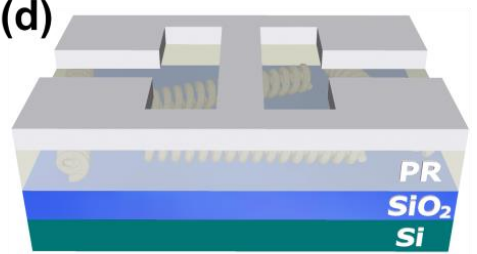

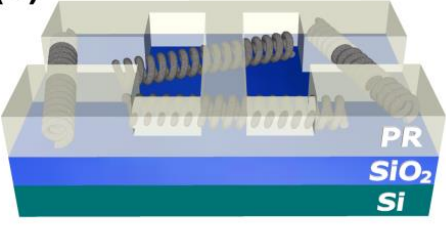

(g)

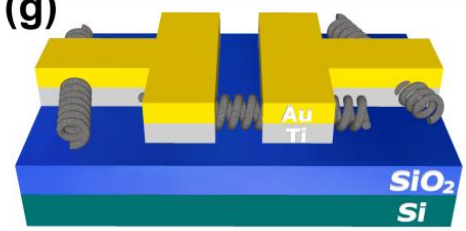

Figure 2. Schematic representation of the device fabrication process. (a) GUITAR-coated nanosprings (G-NSs) released into IPA and (b) drop-cast onto a $\mathrm{SiO}_{2} / \mathrm{Si}$ substrate. (c) Photoresist (PR) is spun onto the substrate. (d) UV light is exposed to photoresist with a chrome mask in place to create the electrode pattern. (e) The photoresist exposed to UV is removed with a developer. (f) Ti and Au are deposited via thermal evaporation and the remaining photoresist is removed in a solution of photoresist remover. (g) The electrode gap is cleared of G-NSs via a micromanipulator until one G-NS remains with sufficient contact. 


\subsection{Electrical Measurements and Microscopy Equipment}

Electrical measurements were acquired using a Keithley Model 2400 (Tektronix, Beaverton, OR, USA) and two Model 110 micromanipulators (The Micromanipulator Co., Carson City, NV, USA). The single G-NS devices were heated by placing the devices on a single stage thermoelectric cooler powered with an HP Model 6033A (Hewlett-Packard, Palo Alto, CA, USA) power supply. The device temperature was monitored with an Omega Model HH12 (Omega Engineering, Norwalk, CT, USA) digital thermometer. Atomic force microscopy (AFM) images were obtained with a Veeco Autoprobe Di CP-II (Veeco, Plainview, NY, USA) operating in noncontact mode with a $1 \mathrm{~Hz}$ scan rate. SEM images were obtained with a Zeiss Supra 35 SEM (Zeiss, Peabody, MA, USA). Transmission electron microscopy (TEM) images were obtained with a JEOL 2010J (JEOL USA, Peabody, MA, USA) operating at $200 \mathrm{kV}$.

\subsection{Raman Spectroscopy}

In order to investigate the excitation wavelength dependence of GUITAR's Raman spectrum, Raman spectra of GUITAR thin films were collected using five different laser excitation wavelengths: $442 \mathrm{~nm}(\mathrm{HeCd}), 488 \mathrm{~nm}$ and $514 \mathrm{~nm}$ (Ar ion), $532 \mathrm{~nm}$ (frequency doubled Nd:YAG), and $633 \mathrm{~nm}(\mathrm{HeNe})$. The Raman spectra at excitation wavelengths of $442 \mathrm{~nm}, 532 \mathrm{~nm}$, and $633 \mathrm{~nm}$ were obtained with a LabRAM HR Evolution confocal Raman microscope (Horiba Scientific, Piscataway, NJ, USA) using a $100 \times 0.90$ NA ultrashort $(210 \mu \mathrm{m})$ working distance Olympus objective, which produced a spot size of $\sim 600-900 \mathrm{~nm}$ at the sample surface depending on the excitation wavelength. Spectra were dispersed onto a thermoelectrically cooled CCD array detector using an 1800 line/mm grating blazed for visible wavelengths. Two $30 \mathrm{~s}$ accumulations were averaged to maximize signal to noise and enable removal of cosmic rays from the spectra. Neutral density filters were inserted into the excitation beam until no evidence of thermal (i.e., sample heating) or nonlinear (power) effects were seen in the resultant spectra. The system used for acquisition of Raman spectra at excitation wavelengths of $488 \mathrm{~nm}$ and $514 \mathrm{~nm}$ consisted of a Coherent Innova 90-3 argon ion laser (Coherent, Santa Clara, CA, USA) and a Horiba Jobin Yvon T64000 triple monochromator (Horiba Scientific, Piscataway, NJ, USA) equipped with a 2400 line/mm grating and a liquid nitrogen cooled CCD array detector. Spectra were collected at a laser power of $200 \mathrm{~mW}$ with a spot size of $\sim 100 \mu \mathrm{m}$, corresponding to a power density $\sim 2$ orders of magnitude lower than the Raman microscope system and, thus, well below the threshold for any thermal or power effects. To ensure the Raman spectra obtained were representative, multiple locations across multiple samples were analyzed with both Raman systems.

\section{Results and Discussion}

\subsection{Raman Spectroscopy}

Figure 3a shows a Raman spectrum with a $532 \mathrm{~nm}$ excitation source of a GUITAR coating on a silicon substrate. Figure $3 b$ shows the corresponding AFM image of the surface of GUITAR on a silicon substrate. The surface is an agglomeration of carbon spheroids $\sim 50 \mathrm{~nm}$ in diameter. A discussion of the surface morphology is presented in the following section. The Raman spectrum in Figure $3 a$ consists of two prominent peaks located at $1347 \mathrm{~cm}^{-1}$ and $1589 \mathrm{~cm}^{-1}$, as well as a broad peak centered at $\sim 2800 \mathrm{~cm}^{-1}$. The peak at $1589 \mathrm{~cm}^{-1}$, also known as the $\mathrm{G}$ peak, is attributed to a phonon with $\mathrm{E}_{2 \mathrm{~g}}$ symmetry and is associated with in-plane bond stretching of pairs of $\mathrm{sp}^{2}$ hybridized carbon atoms [21,32]. The wavenumber of the $G$ peak falls in the range of $1500-1630 \mathrm{~cm}^{-1}$ and does not require the presence of six-fold rings, i.e., it is present for all sp $\mathrm{sp}^{2}$ bonding [32]. The peak located at $1347 \mathrm{~cm}^{-1}$, commonly denoted as the $\mathrm{D}$ peak, originates from a phonon with $\mathrm{A}_{1 \mathrm{~g}}$ symmetry [21]. The D peak, in conjunction with the $G$ peak, is only observed in the presence of disorder and is not present in the Raman spectra of ideal graphite [21,32]. A small, yet notable, feature is present on the shoulder of the D peak at $\sim 1150 \mathrm{~cm}^{-1}$. This peak is commonly used to characterize nanocrystalline diamond and attributed to $\mathrm{sp}^{3}$ bonding [33-36]. However, Ferrari et al. argue that this peak must originate from an alternate chain of $\mathrm{sp}^{2}$ carbon atoms formed by a single hydrogen bonded to each $\mathrm{C}$ [37]. 
A previous study of GUITAR using XPS showed that the material could possibly contain alternate chains of $\mathrm{sp}^{2}$-bonded carbon atoms, such as $\mathrm{C}=\mathrm{N}$, which could account for the peak at $\sim 1150 \mathrm{~cm}^{-1}$ [1].
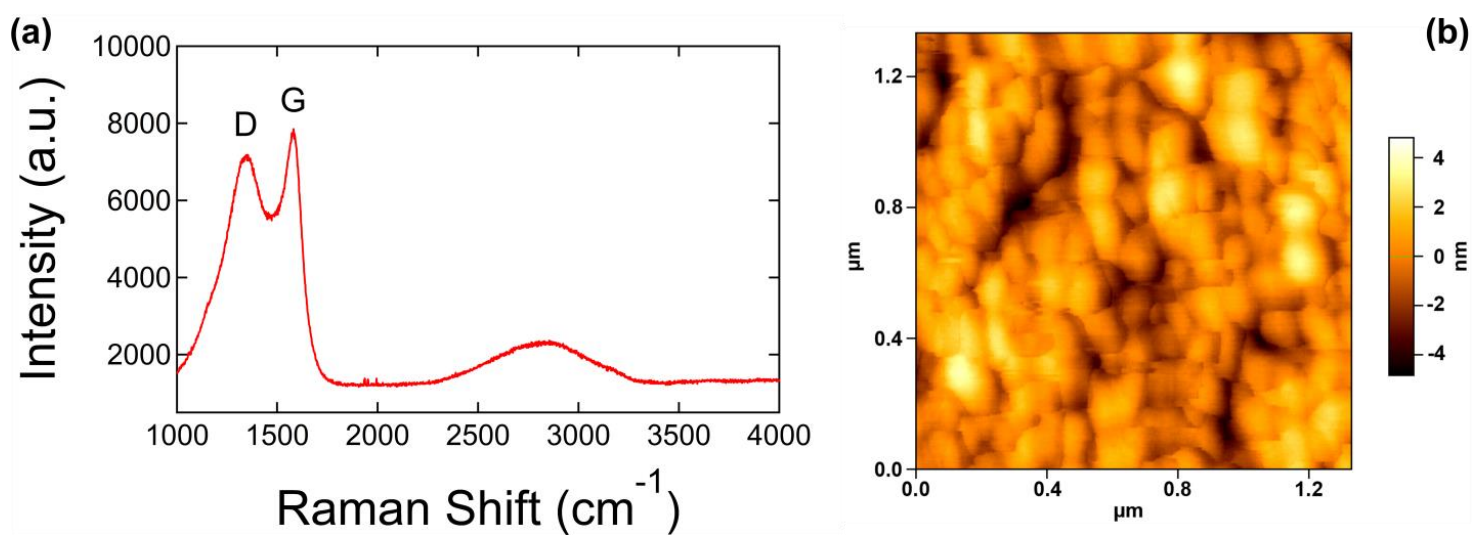

Figure 3. (a) Raman spectrum of GUITAR on a silicon substrate obtained with a $532 \mathrm{~nm}$ excitation source and (b) an AFM image of GUITAR on a silicon substrate showing GUITAR's surface morphology, which is comprised of an agglomeration of carbon spheroids $\sim 50 \mathrm{~nm}$ in diameter.

Ferrari and Robertson studied the visible Raman spectra of disordered carbons and presented a three stage model of disorder from graphite to amorphous carbon that simplified the characterization of Raman spectra for all types of carbons [32]. The stages from ordered to disordered are as follows: Stage (1), graphite to nanocrystalline graphite (nc-G); Stage (2), nc-G to amorphous carbon with a small $\mathrm{sp}^{3}$ content (a-C); Stage (3), a-C to tetrahedral amorphous carbon with a high $\mathrm{sp}^{3}$ content (ta-C) [32]. Each stage has unique features in its Raman spectra, which can be used to distinguish between the three stages. Most notable in the Raman spectrum of Figure 3a are the broad peak located at $\sim 2800 \mathrm{~cm}^{-1}$ and the absence of well-defined second order G or D peaks. The span of the broad peak is from $\sim 2300-3200 \mathrm{~cm}^{-1}$. It is a feature that is only present in the evolution of Stage (2) of nc-G to a-C $[32,38]$ and is a combination of the $2 \mathrm{D}, \mathrm{D}+\mathrm{D}^{\prime}$, and $2 \mathrm{D}^{\prime}$ bands [32,39].

The excitation energy dependence of GUITAR's Raman spectrum provides further evidence that GUITAR corresponds to Stage (2) carbon formation. Figure 4a shows the Raman spectra of GUITAR with $1.96 \mathrm{eV}(633 \mathrm{~nm}), 2.33 \mathrm{eV}(532 \mathrm{~nm}), 2.41 \mathrm{eV}(514 \mathrm{~nm}), 2.54 \mathrm{eV}(488 \mathrm{~nm})$, and $2.81 \mathrm{eV}(442 \mathrm{~nm})$ excitation energies (wavelengths). The Raman spectrum for each excitation energy was fitted with a Lorentzian line shape for the D peak and a Breit-Wigner-Fano (BWF) line shape for the G peak. The BWF line shape function is as Equation (1),

$$
I(\omega)=\frac{I_{0}\left[1+2\left(\omega-\omega_{0}\right) / Q \Gamma\right]^{2}}{1+\left[2\left(\omega-\omega_{0}\right) / \Gamma\right]^{2}}
$$

where $I$ is the intensity, $\omega$ is the frequency, $I_{0}$ is the peak intensity, $\omega_{0}$ is the peak position, $\Gamma$ is the full width at half maximum, and $Q$ is the BWF coupling coefficient. A Lorentzian shape is recovered in the limit $Q^{-1} \rightarrow 0$. The asymmetry of the BWF line can account for lower frequency Raman features at $\sim 1100 \mathrm{~cm}^{-1}$ and $1400 \mathrm{~cm}^{-1}$ without the addition of two extra peaks [32], and the combination of the BWF and Lorentzian lines is a good fit for the Raman spectral features of all types of carbons and excitation energies [32]. We also define the $G$ peak position as $\omega_{\max }$ in Equation (2):

$$
\omega_{\max }=\omega_{0}+\frac{\Gamma}{2 Q}
$$

where $\omega_{0}$ lies at higher frequencies because $Q$ is negative and is the position of the undamped mode, and is therefore higher than the apparent $G$ peak maximum [32]. We also define the ratio of the intensity of the D and G peaks $(I(D) / I(G)$ ) using the peak heights of the $D$ and $G$ bands rather than the 
peak areas, which is common when using two Gaussian fits for the $D$ and $G$ peaks. The positions of the $D$ and $G$ peak are plotted as a function of excitation energy in Figure $4 \mathrm{~b}$. The vertical error bars in Figure $4 \mathrm{~b}$ are smaller than the markers on the plot. The dispersion of the $\mathrm{D}$ peak as a function of excitation energy is $\sim 48 \mathrm{~cm}^{-1} / \mathrm{eV}$ and is consistent with the dispersion of the Raman D peak of microcrystalline graphite [40]. The dispersion of the D peak is present in the Raman spectra of all types of carbons and has been observed to have an inverse relationship with the degree of disorder [41]. We observed that the $G$ peak position has little to no dependence with excitation energy and remains roughly flat at $\sim 1580 \mathrm{~cm}^{-1}$, as shown in Figure $4 \mathrm{~b}$. These results are consistent with studies of the dispersion of the Raman $G$ band of microcrystalline graphite, where Póscik et al. observed the $G$ peak position to be independent of excitation energies ranging from $\sim 1 \mathrm{eV}$ to $4.5 \mathrm{eV}$ and at a band position of $\sim 1580 \mathrm{~cm}^{-1}$ [40]. In disordered carbons, the position of the $\mathrm{G}$ peak is positively correlated with excitation energy, and the degree of its dispersion increases with disorder [41]. For Stage (2) carbon, the position of the $G$ peak decreases from $\sim 1600 \mathrm{~cm}^{-1}$ to $1510 \mathrm{~cm}^{-1}$ for nc-G to a-C [32]. Additionally, the $G$ peak does not disperse in nc-G [41], which suggests that GUITAR lies somewhere near the beginning of Stage (2) carbon formation, characteristic of nc-G with a low sp ${ }^{3}$ content.

(a)

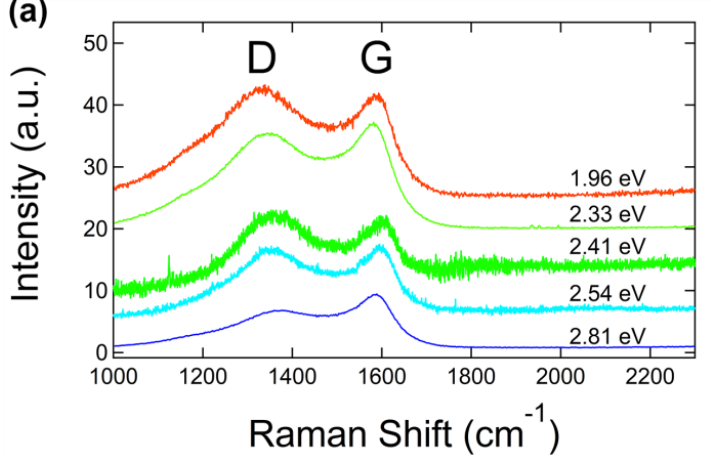

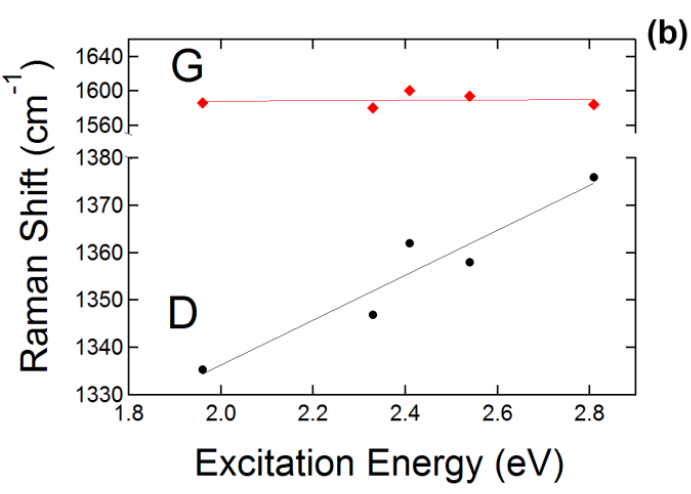

(b)

Figure 4. (a) The Raman spectra of GUITAR for a variety of excitation energies showing the prominent $\mathrm{D}$ and $\mathrm{G}$ peaks, and (b) the positions of the $\mathrm{D}$ and $\mathrm{G}$ peaks plotted as a function of excitation energy.

The $I(\mathrm{D}) / I(\mathrm{G})$ ratio alone cannot be used to accurately estimate the $\mathrm{sp}^{3}$ fraction of Stage (2) carbon. Ferrari et al. studied the Raman spectra of both an amorphization trajectory and an ordering trajectory with independent measures of the $\mathrm{sp}^{3}$ fractions for each stage. They found a hysteresis cycle that shows no relationship between the $I(D) / I(G)$ ratio or the position of the $G$ peak and the $\mathrm{sp}^{3}$ fraction [32]. The $I(\mathrm{D}) / I(\mathrm{G})$ ratio can, however, be used to estimate the crystalline size, $L_{a}$ [21]. Tuinstra and Koenig showed that the $I(\mathrm{D}) / I(\mathrm{G})$ ratio is inversely proportional to the average crystal size using the relationship, $I(D) / I(G)=C(\lambda) / L_{a}$, where $C(514 \mathrm{~nm}) \sim 4.4 \mathrm{~nm}[20,21,42]$. In the evolution of Stage (2) carbon, the $I(\mathrm{D}) / I(\mathrm{G})$ ratio approaches zero and the Tuinstra-Koenig relation is no longer valid. Ferrari and Robertson proposed the following new relationship for a carbon nearing the end of Stage (2) and approaching that of a-C and the regime of $L_{\mathrm{a}}<2 \mathrm{~nm}: I(\mathrm{D}) / I(\mathrm{G})=C^{\prime}(\lambda) L_{a}^{2}$, where $C^{\prime}(514 \mathrm{~nm})$ $\sim 0.0055$ [32]. Figure 5 shows the ratio of the intensities of the $D$ and $G$ peaks plotted as a function of excitation energy. The features of the Raman spectra to this point are characteristic of nc-G with a low $\mathrm{sp}^{3}$ content, which in Ferrari's three stage disorder spectrum lies somewhere in the beginning of Stage (2), yet its exact location in the evolution of Stage (2) is undetermined. We therefore estimated the crystal size using both the Tuinstra-Koenig and the Ferrari-Robertson relationship. We found that for a $514 \mathrm{~nm}$ source, the GUITAR crystal size was $\sim 1.5 \mathrm{~nm}$ using the Ferrari-Robertson relationship and $\sim 3.6 \mathrm{~nm}$ using the Tuinstra-Koenig relationship, setting limits on the crystal size of $1.5 \mathrm{~nm} \leq L_{\mathrm{a}} \leq 3.6 \mathrm{~nm}$. 


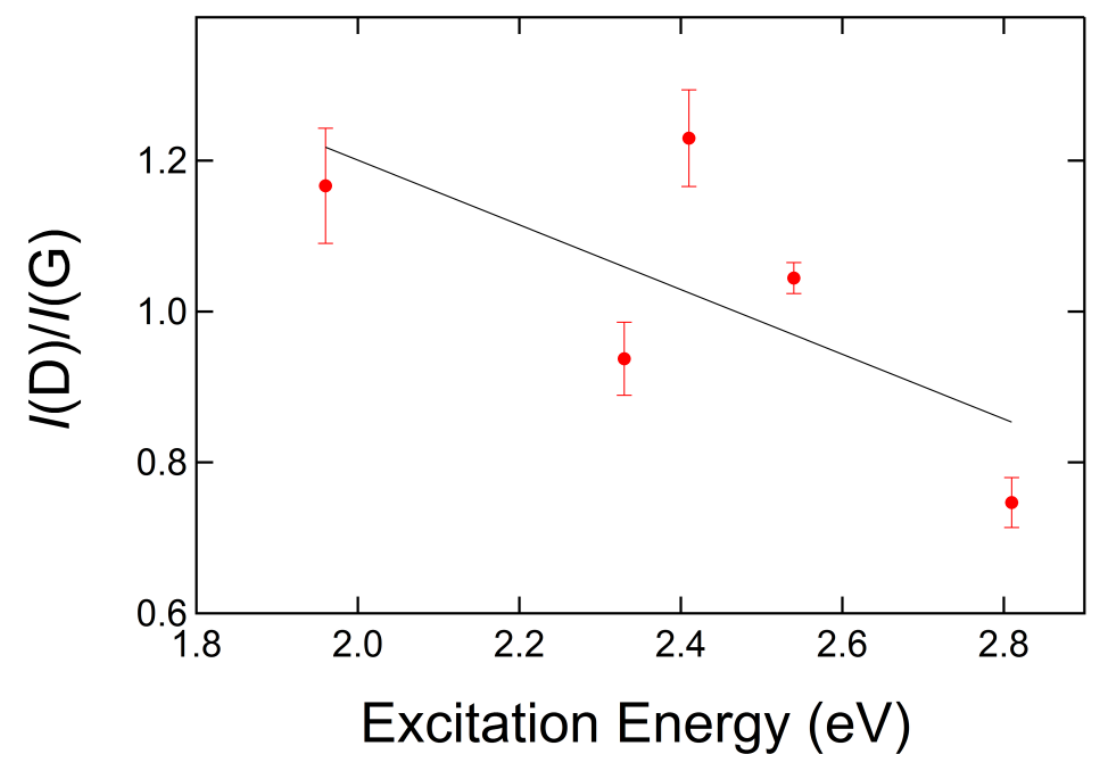

Figure 5. The ratio of the intensities of the $D$ and $G$ peaks as a function of excitation energy.

\subsection{GUITAR Surface Morphology}

Figure 6a is an SEM image of the G-NS surface that exhibits a pattern of smooth hemispheres $\sim 50-100 \mathrm{~nm}$ in diameter. Figure $6 \mathrm{~b}$ is a TEM image of a single G-NS. The TEM image in Figure $6 \mathrm{c}$ is a lateral view of the surface of a single G-NS, showing the GUITAR/NS interface with an outset showing a detailed view of one carbon nanosphere. The TEM images in Figure $6 b, c$ show the inner core of the NS, which is comprised of several individual silica nanowires bundled together to form a larger, helical structure $\sim 1 \mu \mathrm{m}$ in diameter. The GUITAR coating is visible on the outer edge of the NS and the GUITAR/NS interface is well defined. Bare silicon substrates were placed alongside the bulk NS samples during the deposition of GUITAR to compare the surface morphology of GUITAR on NSs and on a flat surface. The surface morphology of GUITAR on a flat silicon substrate, as shown in the AFM image in Figure 3b, resembles that of GUITAR on a NS and confirms the presence of an agglomeration of hemispheres $\sim 50-100 \mathrm{~nm}$ in diameter. TEM images of eight individual G-NSs were used to calculate the average thickness of the GUITAR coating. For each of the eight G-NSs, $\sim 5-10$ locations were chosen to measure the thickness of the coating. The total average thickness of the GUITAR coating was $87 \pm 32 \mathrm{~nm}$. The AFM image in Figure $3 \mathrm{~b}$ is consistent with both the SEM and TEM images in Figure $6 \mathrm{a}-\mathrm{c}$, and these images together show that the GUITAR coating is a $\sim 100 \mathrm{~nm}$ thick layer comprised of an agglomeration of irregularly shaped carbon nanospheres with diameters ranging from $\sim 50-100 \mathrm{~nm}$.

Micrometer-sized and nanometer-sized carbon-shaped spheres have been produced via a plethora of methods, and a comprehensive study of the variety of morphologies has been conducted. Inagaki et al. proposed that spherical carbon bodies could be classified into three categories based on their nanometric texture, e.g., the concentric, radial, and random arrangement of the carbon layers [43]. Serp et al. further classified spherical carbons with three additional categories based on their size: carbon onions and the $C_{n}$ family, with diameters ranging from 2-20 nm; carbon nanospheres that exhibit a small degree of graphitization and that have diameters ranging from $50 \mathrm{~nm}$ to $1 \mu \mathrm{m}$; and carbon beads that range in diameter from one to several microns [44]. Inagaki classified carbon nanospheres produced from the thermal decomposition of hydrocarbon gases as carbon blacks and proposed a concentric arrangement of carbon layers [43]. This concentric texture has been observed with TEM and shows that carbon nanospheres are composed of graphitic layers with unclosed graphitic flakes on their surfaces $[45,46]$. Carbon nanospheres are also generally observed as an agglomeration of carbon spheres with varying diameters [45,47-50]. The coalescence and accretion of carbon nanospheres was observed by Nieto-Marquez et al. via a catalytic growth method [49], Kang and Wang via catalytic carbonization 
after treatment in acetone [45], and by Jin et al. via the pyrolysis of a variety of hydrocarbons in the absence of a catalyst [48]. The accretion of carbon nanospheres can be attributed to the high surface reactivity resulting from dangling bonds on the unclosed graphitic flakes residing on the surface of the spheres $[45,46,49]$.
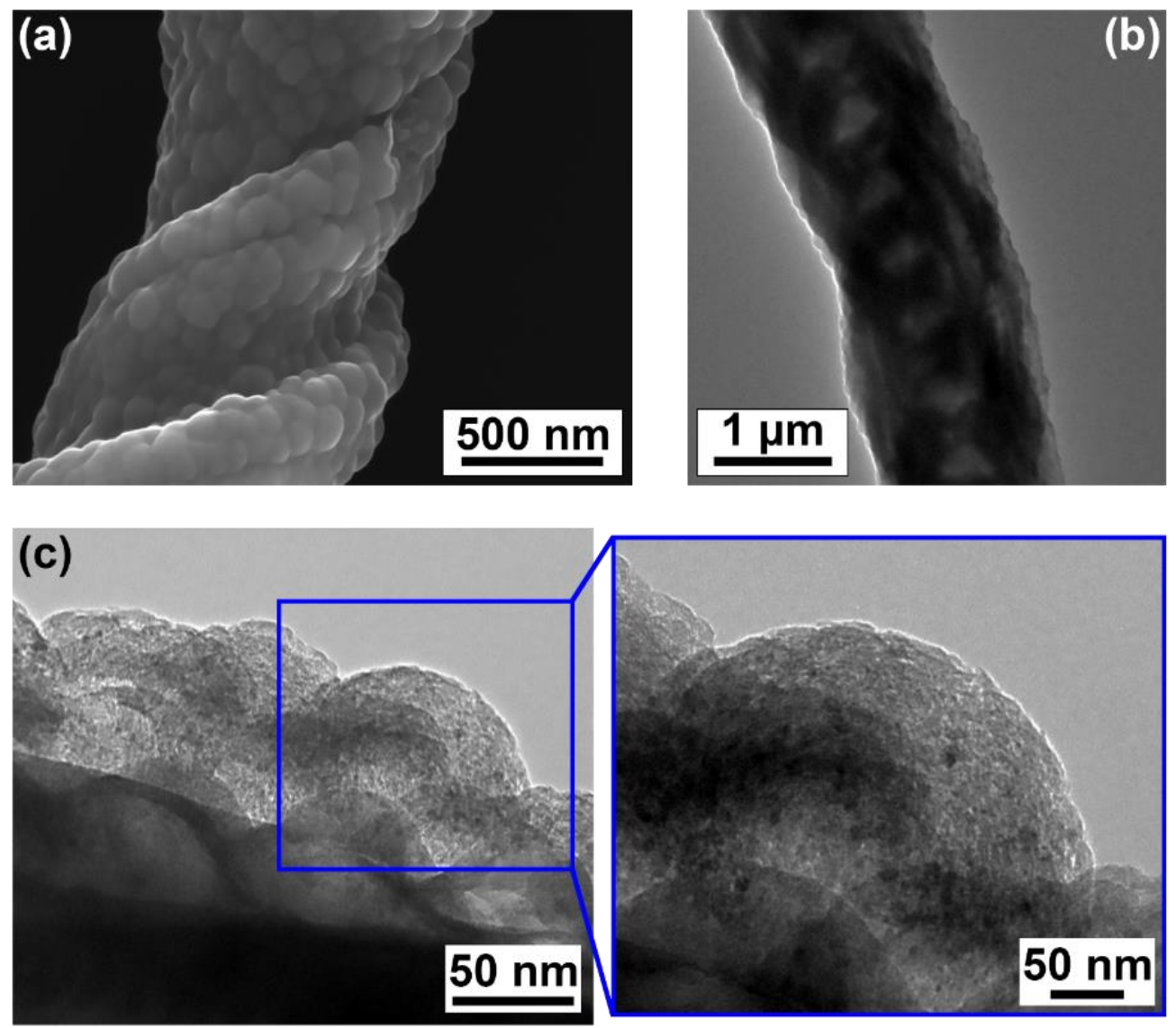

Figure 6. (a) SEM image of the surface of a G-NS. (b) TEM image of a single G-NS showing the GUITAR coating and the inner core of a NS. (c) TEM images of a single G-NS showing the interface of the NS and the GUITAR coating, and outset showing a side view of a single carbon nanosphere within the GUITAR coating.

The outset in Figure 6c shows a detailed view of an individual carbon nanosphere on a NS. The morphology of its outer surface is nonuniform and shows that the sphere's surface is comprised of unclosed graphitic flakes. Upon further inspection of the surface of the individual carbon nanosphere, we found that the flakes are nonuniform disks, which vary in diameter from $\sim 1-5 \mathrm{~nm}$. The sizes of these flakes are consistent with estimations of crystal size according to an analysis of GUITAR's Raman spectra, which showed that $1.5 \mathrm{~nm} \leq L_{\mathrm{a}} \leq 3.6 \mathrm{~nm}$, and the $I(\mathrm{D}) / I(\mathrm{G})$ ratio (Figure 5), which also shows that GUITAR is characteristic of a material with a low degree of graphitization. All of these features demonstrate that the building block of the GUITAR coating is a carbon nanosphere, per the description by Serp et al. and Inagaki et al., which agglomerate to form a film or coating in the case of the NSs.

\subsection{Electrical Characteristics}

Figure 7a shows an SEM image of a typical single G-NS device spanning a $6 \mu \mathrm{m}$ gap between two $\mathrm{Ti} / \mathrm{Au}$ source-drain electrodes. Figure $7 \mathrm{~b}$ shows a typical two-point probe source-drain current-voltage $\left(I_{\mathrm{SD}}-V_{\mathrm{SD}}\right)$ curve for a single G-NS device at room temperature and atmospheric pressure. The inset in Figure $7 \mathrm{~b}$ shows a three-dimensional schematic and electrical diagram of the single G-NS device. The $I_{\mathrm{SD}}-V_{\mathrm{SD}}$ curve is linear and indicative of Ohmic contacts. All of the devices tested in this work 
displayed Ohmic behavior. The total resistance $\left(R_{\mathrm{T}}\right)$ obtained from the two-point $I_{\mathrm{SD}}-V_{\mathrm{SD}}$ measurement is the sum of the resistance of the single G-NS $\left(R_{\mathrm{G}-\mathrm{NS}}\right)$ and of the two contact resistances $\left(R_{\mathrm{C}}\right)$ at the GUITAR-Ti/Au interface on each end: $R_{\mathrm{T}}=R_{\mathrm{G}-\mathrm{NS}}+2 R_{\mathrm{C}}$. Previous studies on the contact resistance of single- and multilayered graphene to Ti/Au metal contacts have reported contact resistances of $<250 \Omega$ for multilayered graphene ( $\sim 50$ layers) [51], and $\sim 165 \Omega$ for single-layered graphene [52]. A comparison of the contact resistances for Ni contacts on graphene and highly ordered pyrolytic graphite (HOPG) has shown that the measurements are approximately two orders of magnitude higher for Ni contacts on graphene than on HOPG. This greater contact resistance is attributed to the higher charge density in HOPG [51]. Additionally, Venugopal et al. have shown that the contact resistance for metal contacts on multilayered graphene decreases as the number of graphene layers increases [51]; this is because increasing the number of graphene layers results in increased carrier concentration, until the structure approaches that of HOPG, i.e., becomes more metallic. Since the GUITAR coating is characteristic of a disordered multilayered graphitic material, it must have a high charge density, representative of multilayered graphene and HOPG. Therefore, the contact resistance of the GUITAR-Ti/Au is small $(<250 \Omega)$, or $\sim 3$ orders of magnitude smaller than the total resistance of a single G-NS $(\sim 500 \mathrm{k} \Omega)$, and therefore can be neglected.
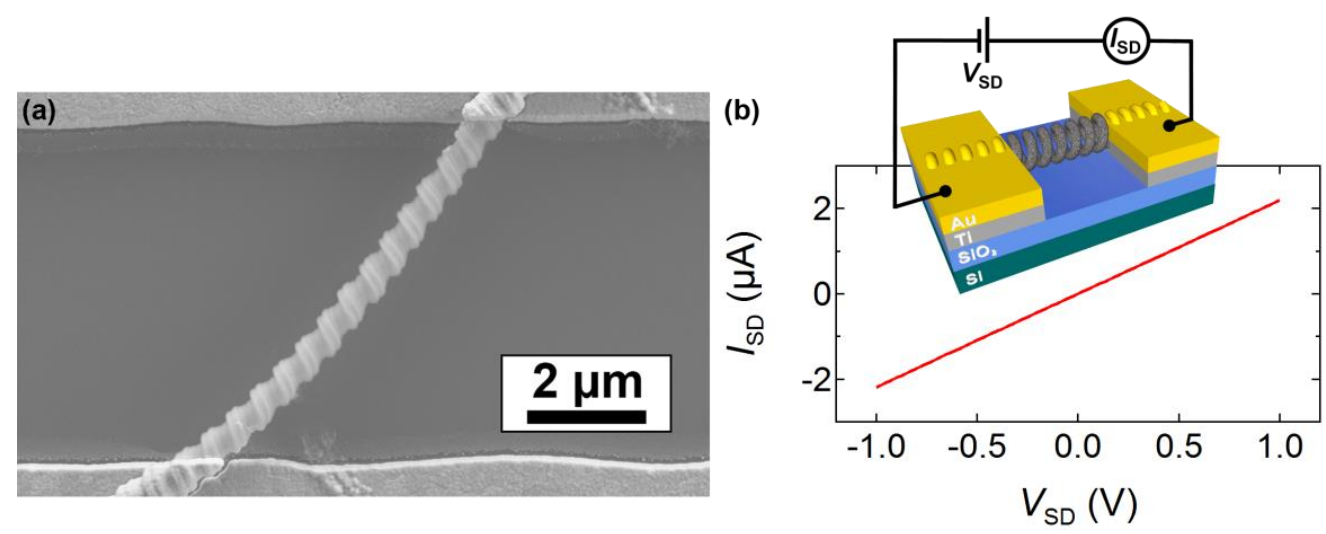

Figure 7. (a) SEM image of a single G-NS between two source-drain Ti/Au electrodes, and (b) the Ohmic $I_{\mathrm{SD}}-V_{\mathrm{SD}}$ curve of a typical G-NS device and an inset showing a three-dimensional representation of the device and the corresponding electrical diagram.

The single G-NS devices failed when the magnitude of $I_{\mathrm{SD}}$ exceeded $\sim 10 \mu \mathrm{A}$. Care was taken to avoid applying a large current by keeping the magnitude of $V_{\mathrm{SD}}$ below $3 \mathrm{~V}$. A gate voltage was applied to the G-NS via a back-gate. $I_{\mathrm{SD}}-V_{\mathrm{SD}}$ curves were measured while the back-gate voltage was held constant. There was no observable change in the resistance for back-gate voltages ranging from $-20 \mathrm{~V}$ to $20 \mathrm{~V}$, suggesting that the device did not exhibit a field effect, and therefore confirming that it is not semiconducting.

Eleven single G-NS devices were used to determine the average resistivity and conductivity of the GUITAR coating. The resistivity ( $\rho$ ) of each device was calculated using Equation (3):

$$
\rho=R \frac{A}{L}
$$

where $R$ is the average resistance of the device, $A$ is the cross-sectional area of the GUITAR coating on the NS, and $L$ is the length of the G-NS. For each single G-NS device, the slopes of five $I_{\mathrm{SD}}-V_{\mathrm{SD}}$ curves from $\pm 1 \mathrm{~V}$ were taken at $20^{\circ} \mathrm{C}$ and used to calculate the average resistance for each device. The cross-sectional area of the GUITAR coating was determined from the average thickness of the GUITAR coating calculated from the TEM images, as described in Section 3.2. SEM images of each device were used to determine the radius and length of the NS. The helical pitch of an individual NS is random and uncontrollable during the growth process. Therefore, the helical pitches of the single 
G-NS devices are also random. However, the helical pitch of the single G-NS devices in this study were well-defined and constant along the entire span of the electrode gap, meaning the G-NS can be represented as a helix with constant radius in the active region of each device, which allowed for the calculation of the wire diameter and length of each G-NS. In some instances, the pitch of the G-NS was small, so that adjacent coils are in contact with one another, creating a closed coil along the entire length of its active area in the device. In this case, the G-NS was treated as a wire and an average diameter was calculated over the pitch of two adjacent coils. The average resistivity calculated from the slopes of five $I_{\mathrm{SD}}-V_{\mathrm{SD}}$ curves at $20^{\circ} \mathrm{C}$ for each device are shown in Table 1 . The total average resistivity of the 11 single G-NS devices at $20^{\circ} \mathrm{C}$ is $4.3 \pm 1.3 \times 10^{-3} \Omega \mathrm{m}$.

Table 1. The average resistivity of the 11 single G-NS devices calculated from the slopes of five $I_{\mathrm{SD}}-V_{\mathrm{SD}}$ curves at $20^{\circ} \mathrm{C}$ for each device.

\begin{tabular}{cc}
\hline Device & Average Resistivity $(\boldsymbol{\Omega} \mathbf{~ m})$ at $20^{\circ} \mathbf{C}$ \\
\hline 1 & $3.1 \pm 0.62 \times 10^{-3}$ \\
2 & $20 \pm 3.8 \times 10^{-3}$ \\
3 & $7.4 \pm 1.4 \times 10^{-3}$ \\
4 & $3.6 \pm 0.75 \times 10^{-3}$ \\
5 & $2.1 \pm 0.62 \times 10^{-3}$ \\
6 & $4.9 \pm 1.1 \times 10^{-3}$ \\
7 & $1.6 \pm 0.18 \times 10^{-3}$ \\
8 & $1.3 \pm 0.25 \times 10^{-3}$ \\
9 & $1.2 \pm 0.19 \times 10^{-3}$ \\
10 & $1.6 \pm 0.34 \times 10^{-3}$ \\
11 & $0.92 \pm 0.16 \times 10^{-3}$ \\
\hline
\end{tabular}

The temperature-dependent $I_{\mathrm{SD}}-V_{\mathrm{SD}}$ curves of a single G-NS (device 3) from $10-80{ }^{\circ} \mathrm{C}$ in increments of $10^{\circ} \mathrm{C}$ are displayed in Figure 8a. The inset in Figure 8a shows the upper range of the $I_{\mathrm{SD}}-V_{\mathrm{SD}}$ plot and the device's linear change in resistance as a function of temperature. Note that the $I_{\mathrm{SD}}-V_{\mathrm{SD}}$ curve remains Ohmic across the entire temperature range. The slopes of five $I_{\mathrm{SD}}-V_{\mathrm{SD}}$ curves were used to calculate the average resistivity at each temperature, which are presented in Figure $8 \mathrm{~b}$. The vertical errors bars are smaller than the markers used in the plot. The resistivity of the device is linear with respect to temperature and decreases at $\sim-1.8 \times 10^{-5} \Omega \mathrm{m} /{ }^{\circ} \mathrm{C}$, i.e., has a negative slope.

The linear relationship between resistivity and temperature was used to calculate the negative temperature coefficient of resistivity (TCOR) at $20^{\circ} \mathrm{C}$. The resistivity of the G-NS can be expressed as a function of the temperature $(T)$ as Equation (4):

$$
\rho(T)=\rho_{0}\left[1+\alpha_{0}\left(T-T_{0}\right)\right]
$$

where $T_{0}$ is the reference temperature at $20^{\circ} \mathrm{C}, \rho_{0}$ is the resistivity at the reference temperature, and $\alpha_{0}$ is the TCOR at $20^{\circ} \mathrm{C}$. For each of the 11 single G-NS devices, the slope of the resistivity vs. temperature profiles $(\Delta \rho / \Delta T)$ were obtained from a linear fit of the data, as shown in Figure 8 b. The resistivity at the reference temperature of $20^{\circ} \mathrm{C}$ for each device (Table 1) and $\Delta \rho / \Delta T$ were used to calculate $\alpha_{0}$ with Equation (5):

$$
\alpha_{0}=(\Delta \rho / \Delta T) \rho_{0}{ }^{-1} .
$$

All of the single G-NS devices displayed equivalent temperature dependence, as shown in Figure $8 \mathrm{a}, \mathrm{b}$ and Table 2 . The slope of the resistivity vs. temperature profile, the resistivity at the reference temperature $\left(\rho_{0}\right)$, and the calculated TCOR for each device are shown in Table 2 . The average TCOR of the 11 single G-NS devices at $20^{\circ} \mathrm{C}$ was $-0.0017 \pm 0.00044{ }^{\circ} \mathrm{C}^{-1}$. 

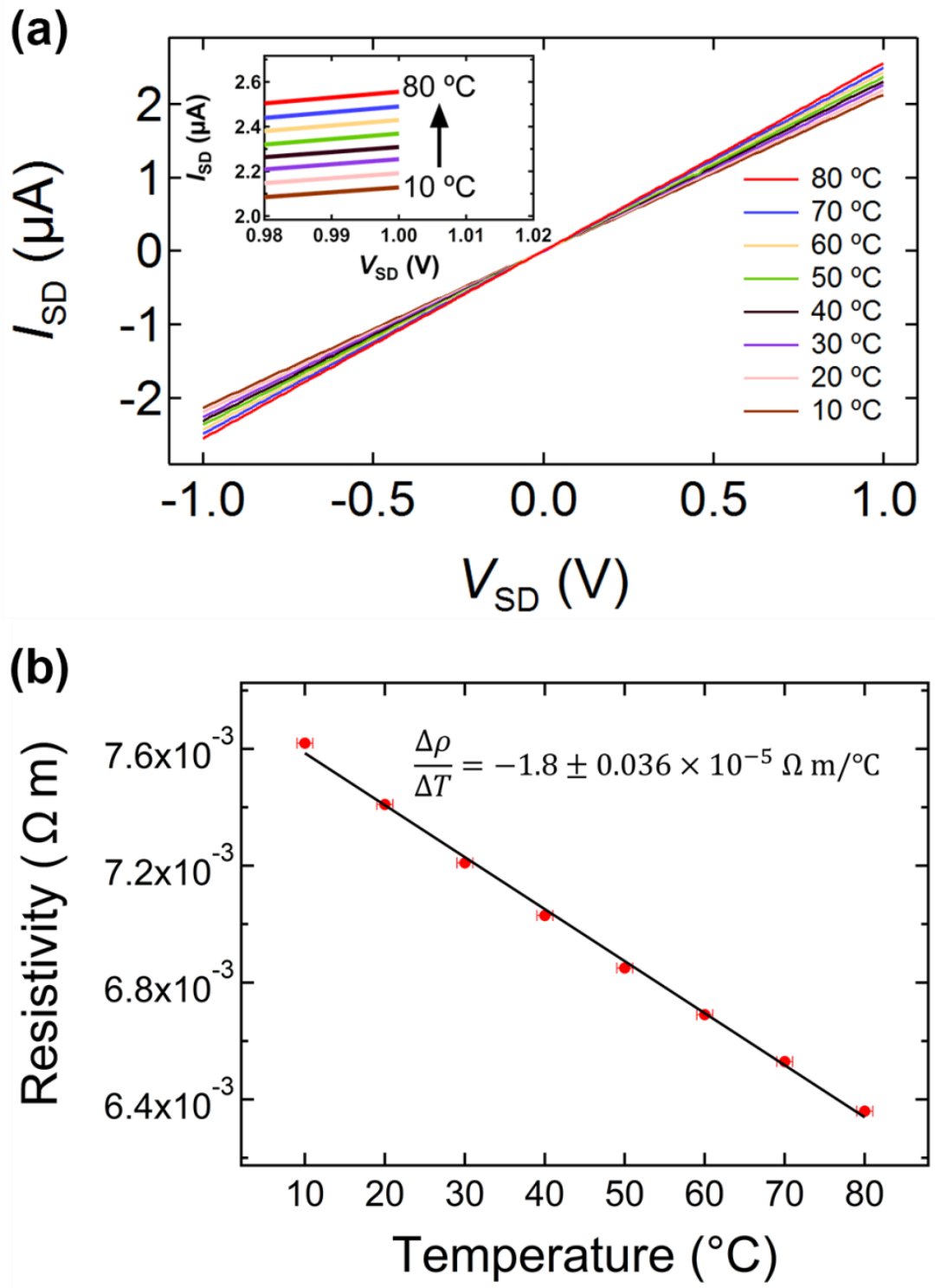

Figure 8. (a) Temperature dependent $I_{\mathrm{SD}}-V_{\mathrm{SD}}$ curves of a single G-NS (device 3 ) from $10-80{ }^{\circ} \mathrm{C}$, where the inset is an expanded view of the upper range of $I_{\mathrm{SD}}-V_{\mathrm{SD}}$, and (b) the resistivity vs. temperature profile for the same single G-NS, which displays a negative linear slope.

Table 2. The slope of the resistivity vs. temperature profile $(\Delta \rho / \Delta T)$, the resistivity at the reference temperature $\left(\rho_{0}\right)$, and the calculated TCOR for each device.

\begin{tabular}{cccc}
\hline Device & $\Delta \rho / \Delta T\left(\Omega \mathrm{m} /{ }^{\circ} \mathrm{C}\right)$ & $\rho_{0}(\boldsymbol{\Omega} \mathrm{m})$ & TCOR $\left({ }^{\circ} \mathrm{C}^{-1}\right)$ \\
\hline 1 & $-8.9 \pm 1.2 \times 10^{-6}$ & $3.1 \pm 0.62 \times 10^{-3}$ & $-2.9 \pm 0.69 \times 10^{-3}$ \\
2 & $-5.0 \pm 1.5 \times 10^{-5}$ & $20 \pm 3.8 \times 10^{-3}$ & $-2.5 \pm 0.88 \times 10^{-3}$ \\
3 & $-1.8 \pm 0.036 \times 10^{-5}$ & $7.4 \pm 1.4 \times 10^{-3}$ & $-2.4 \pm 0.46 \times 10^{-3}$ \\
4 & $-3.1 \pm 0.32 \times 10^{-6}$ & $3.6 \pm 0.75 \times 10^{-3}$ & $-0.87 \pm 0.20 \times 10^{-3}$ \\
5 & $-3.7 \pm 0.097 \times 10^{-6}$ & $2.1 \pm 0.62 \times 10^{-3}$ & $-1.8 \pm 0.52 \times 10^{-3}$ \\
6 & $-7.9 \pm 0.36 \times 10^{-6}$ & $4.9 \pm 1.1 \times 10^{-3}$ & $-1.6 \pm 0.37 \times 10^{-3}$ \\
7 & $-2.3 \pm 0.032 \times 10^{-6}$ & $1.6 \pm 0.18 \times 10^{-3}$ & $-1.4 \pm 0.17 \times 10^{-3}$ \\
8 & $-1.6 \pm 0.043 \times 10^{-6}$ & $1.3 \pm 0.25 \times 10^{-3}$ & $-1.2 \pm 0.24 \times 10^{-3}$ \\
9 & $-1.3 \pm 0.056 \times 10^{-6}$ & $1.2 \pm 0.19 \times 10^{-3}$ & $-1.0 \pm 0.17 \times 10^{-3}$ \\
10 & $-2.2 \pm 0.049 \times 10^{-6}$ & $1.6 \pm 0.34 \times 10^{-3}$ & $-1.4 \pm 0.29 \times 10^{-3}$ \\
11 & $-1.2 \pm 0.069 \times 10^{-6}$ & $0.92 \pm 0.16 \times 10^{-3}$ & $-1.3 \pm 0.24 \times 10^{-3}$ \\
\hline
\end{tabular}


The electrical resistivity and, in particular, the temperature dependency of the resistivity of carbon NCs, graphite, and other allotropes of carbon are well-known and have been studied extensively [7-19]. At and near room temperature, the temperature dependence of the resistivity for conductive carbons is linear and the TCOR can be calculated using Equation (5). The calculated TCOR of a variety of conductive carbons are summarized in Table 3. Many authors have reported the temperature dependent resistivities for large temperature ranges $(\sim 0 \mathrm{~K}-2000 \mathrm{~K})$, but they did not specifically calculate the TCOR in the room temperature regime. All of the TCOR values listed in Table 3 except for GUITAR were extrapolated from the linear regime of the resistivity vs. temperature plots near room temperature and for $\Delta T \sim 100{ }^{\circ} \mathrm{C}$.

Table 3. Comparison of the resistivities, conductivities, and TCOR values for a variety of materials, including GUITAR.

\begin{tabular}{|c|c|c|c|c|}
\hline Material & $\begin{array}{c}\text { Resistivity } \\
\rho(\Omega \mathrm{m}) \text { at } 20^{\circ} \mathrm{C}\end{array}$ & $\begin{array}{l}\text { Conductivity } \\
\sigma(\mathrm{S} / \mathrm{m}) \text { at } 20^{\circ} \mathrm{C}\end{array}$ & $\begin{array}{c}\text { Temperature Coefficient } \\
\text { at } 20^{\circ} \mathrm{C}\left({ }^{\circ} \mathrm{C}^{-1}\right)\end{array}$ & Reference \\
\hline GUITAR & $4.3 \times 10^{-3}$ & $2.3 \times 10^{2}$ & -0.0017 & This Study \\
\hline Carbon Onions & $2.5 \times 10^{-3}$ & $4.0 \times 10^{2}$ & N/A & [53] \\
\hline Carbon Black & $1.7 \times 10^{-3}$ & $6.0 \times 10^{2}$ & -0.00094 & [9] \\
\hline a-C (70 nm thick) & $1.0 \times 10^{-3}$ & $1.0 \times 10^{3}$ & N/A & [7] \\
\hline Graphitized Soot & $3.3 \times 10^{-4}$ & $3.0 \times 10^{3}$ & -0.0014 & [9] \\
\hline Carbon NC & $1.9 \times 10^{-4}$ & $5.3 \times 10^{3}$ & -0.0012 & [18] \\
\hline POCO Graphite AF & $9.6 \times 10^{-5}$ & $1.0 \times 10^{4}$ & -0.0023 & [9] \\
\hline Lampblack Graphite & $5.5 \times 10^{-5}$ & $1.8 \times 10^{4}$ & -0.0013 & [10] \\
\hline Carbon & $4.5 \times 10^{-5}$ & $2.2 \times 10^{4}$ & -0.00040 & [12] \\
\hline Grade AGOT Graphite & $1.0 \times 10^{-5}$ & $9.7 \times 10^{4}$ & -0.0016 & [10] \\
\hline Natural Graphite & $9.8 \times 10^{-6}$ & $1.0 \times 10^{5}$ & -0.0010 & [10] \\
\hline Grade CS Graphite & $7.7 \times 10^{-6}$ & $1.3 \times 10^{5}$ & -0.0017 & [10] \\
\hline Acheson Graphite & $6.3 \times 10^{-6}$ & $1.6 \times 10^{5}$ & -0.0011 & [12] \\
\hline Carbon NC (as grown) & $3.6 \times 10^{-6}$ & $2.8 \times 10^{5}$ & -0.0015 & [19] \\
\hline Carbon NC (annealed) & $4.1 \times 10^{-7}$ & $2.4 \times 10^{6}$ & -0.00072 & [19] \\
\hline
\end{tabular}

The negative temperature dependent resistivity of G-NS is consistent with GUITAR being a graphitic form of carbon. The measured resistivity of GUITAR corresponds with measurements of the resistivity of similarly highly disordered carbon allotropes at room temperature, and it is on the order of the resistivities of an a-C thin film $(70 \mathrm{~nm})$ [7], nanodiamond-derived carbon onion electrodes [53], and carbon black [9]. The resistivity of GUITAR is also within an order of magnitude of the resistivities of graphitized soot [9] and carbon NCs [18] (Table 3). The TEM images of GUITAR in Figure 6 are similar to TEM images of carbon black [54] and graphitized soot [55,56], which is indicative of similar morphologies and chemical compositions, i.e., a low degree of graphitization. The higher conductivities of the remainder of the carbon materials in Table 3 scale with their degree of graphitization.

Using the TCOR alone from Table 3, it is difficult to distinguish a pure graphite from more disordered allotropes of carbon, such as a-C. It is therefore important to consider both the resistivity and the TCOR of GUITAR when classifying it within the spectrum of graphitic materials. GUITAR's negative TCOR near room temperature corresponds with all of the carbon allotropes listed in Table 3 and confirms its classification as a graphitic semimetal material. The Raman spectra, SEM, and TEM images; the negative TCOR at and near room temperature; and the resistivity of GUITAR confirm that it is a graphitic semimetal composed of nc-G.

\section{Conclusions}

We used a combination of Raman spectroscopy, SEM, and TEM images, and the electrical characterization of 11 single G-NS devices to study the nanostructure, surface morphology, electrical resistivity, and negative TCOR of GUITAR in order to classify GUITAR within the spectrum of carbon materials. The Raman spectra of GUITAR were consistent with nc-G, in that it had low sp ${ }^{3}$ content with an estimated crystalline size of $\sim 1.5-3.6 \mathrm{~nm}$. SEM and TEM images show that GUITAR is an 
agglomeration of carbon nanospheres, where their surface is comprised of unclosed graphitic flakes $\sim 1-5 \mathrm{~nm}$ in size. The electrical properties of GUITAR, as determined from the electrical measurements of 11 single G-NS devices, demonstrate that it is a semimetal and that it has properties consistent with those of nc-G. With this study, we have definitively identified GUITAR as a nanocrystalline form of graphite where the $\mathrm{sp}^{2}$ bonded graphite nanocrystals are connected via $\mathrm{sp}^{3}$ bonding. Finally, we have demonstrated the utility of silica NSs as an insulating support for measuring the electrical properties of amorphous and polycrystalline materials, or in this case, GUITAR.

Author Contributions: The experiments and methodology were conceptualized by P.M.W., D.N.M., and I.F.C. D.N.M supervised the research and was responsible for the acquisition of funding. D.E. and P.H.D. supervised the Raman spectroscopy acquisition. P.M.W. performed the NS growth, GUITAR deposition, electrical characterization, acquired the SEM and TEM images, and analyzed all data. N.R. fabricated the single G-NS devices. T.P. acquired the Raman spectroscopy data. H.Z. and P.H.D. wrote a portion of the introduction and Raman spectroscopy experimental details; the rest of the original draft was prepared by P.M.W. The draft was reviewed and edited by D.N.M., P.H.D., and P.M.W.

Funding: This research was funded by a United States Office of Naval Research grant (N00014-17-1-2593). The portion of this work performed at Boise State University was supported by startup funds from the Micron School of Materials Science and Engineering.

Acknowledgments: The authors thank the Boise State Surface Science Laboratory (SSL) for the use of its Horiba LabRAM HR Evolution Raman microscope, as well as Dmitri Tenne of the Boise State Department of Physics for his assistance with Raman spectroscopy and the use of his Raman system.

Conflicts of Interest: The authors declare no conflict of interest.

\section{References}

1. Cheng, I.F.; Xie, Y.; Allen Gonzales, R.; Brejna, P.R.; Sundararajan, J.P.; Fouetio Kengne, B.A.; Eric Aston, D.; Mcllroy, D.N.; Foutch, J.D.; Griffiths, P.R. Synthesis of graphene paper from pyrolyzed asphalt. Carbon 2011, 49, 2852-2861. [CrossRef]

2. Gyan, I.O.; Wojcik, P.M.; Aston, D.E.; McIlroy, D.N.; Cheng, I.F. A Study of the Electrochemical Properties of a New Graphitic Material: GUITAR. ChemElectroChem 2015, 2, 700-706. [CrossRef]

3. Villarreal, C.C.; Pham, T.; Ramnani, P.; Mulchandani, A. Carbon allotropes as sensors for environmental monitoring. Curr. Opin. Electrochem. 2017, 3, 106-113. [CrossRef]

4. Cheng, I.F.; Xie, Y.; Gyan, I.O.; Nicholas, N.W. Highest measured anodic stability in aqueous solutions: Graphenic electrodes from the thermolyzed asphalt reaction. RSC Adv. 2013, 3, 2379. [CrossRef]

5. Gyan, I.O.; Cheng, I.F. Electrochemical study of biologically relevant molecules at electrodes constructed from GUITAR, a new carbon allotrope. Microchem. J. 2015, 122, 39-44. [CrossRef]

6. Kabir, H.; Gyan, I.; Foutch, J.; Zhu, H.; Cheng, I. Application of GUITAR on the Negative Electrode of the Vanadium Redox Flow Battery: Improved V3 +/2 + Heterogeneous Electron Transfer with Reduced Hydrogen Gassing. C 2016, 2, 13. [CrossRef]

7. Morgan, M. Electrical conduction in amorphous carbon films. Thin Solid Film. 1971, 7, 313-323. [CrossRef]

8. Hauser, J.J. Hopping conductivity in amorphous carbon films. Solid State Commun. 1975, 17, 1577-1580. [CrossRef]

9. Romanenko, A.I.; Anikeeva, O.B.; Okotrub, A.V.; Kuznetsov, V.L.; Butenko, Y.V.; Chuvilin, A.L.; Dong, C.; Ni, Y. Temperature Dependence of Electroresistivity, Negative and Positive Magnetoresistivity of Graphite/Diamond Nanocomposites and Onion-Like Carbon. MRS Proc. 2001, 703. [CrossRef]

10. Tyler, W.W.; Wilson, A.C., Jr. Thermal Conductivity, Electrical Resistivity and Thermoelectric Power of Graphite. Phys. Rev. 1953, 89, 870-875. [CrossRef]

11. Powell, R.W.; Schofield, F.H. The thermal and electrical conductivities of carbon and graphite to high temperatures. Proc. Phys. Soc. 1939, 51, 153-172. [CrossRef]

12. Buerschaper, R.A. Thermal and Electrical Conductivity of Graphite and Carbon at Low Temperatures. J. Appl. Phys. 1944, 15, 452-454. [CrossRef]

13. Smith, A.W.; Rasor, N.S. Observed Dependence of the Low-Temperature Thermal and Electrical Conductivity of Graphite on Temperature, Type, Neutron Irradiation, and Bromination. Phys. Rev. 1956, 104, 885-891. [CrossRef] 
14. Mal'tseva, L.F.; Marmer, É.N. Determination of the electrical properties of graphite at high temperatures. Sov. Powder Metall. Met. Ceram. 1962, 1, 34-38. [CrossRef]

15. Adkins, C.J.; Freake, S.M.; Hamilton, E.M. Electrical conduction in amorphous carbon. Philos. Mag. 1970, 22, 183-188. [CrossRef]

16. Matsubara, K.; Sugihara, K.; Tsuzuku, T. Electrical resistance in the $c$ direction of graphite. Phys. Rev. B 1990, 41, 969-974. [CrossRef]

17. Sun, Y.; Wang, C.; Pan, L.; Fu, X.; Yin, P.; Zou, H. Electrical conductivity of single polycrystalline-amorphous carbon nanocoils. Carbon 2016, 98, 285-290. [CrossRef]

18. Ma, H.; Nakata, K.; Pan, L.; Hirahara, K.; Nakayama, Y. Relationship between the structure of carbon nanocoils and their electrical property. Carbon 2014, 73, 71-77. [CrossRef]

19. Fujii, M.; Matsui, M.; Motojima, S.; Hishikawa, Y. Magnetoresistance in carbon micro-coils annealed at various temperatures. J. Cryst. Growth 2002, 237, 1937-1941. [CrossRef]

20. Knight, D.S.; White, W.B. Characterization of diamond films by Raman spectroscopy. J. Mater. Res. 1989, 4, 385-393. [CrossRef]

21. Tuinstra, F.; Koenig, J.L. Raman Spectrum of Graphite. J. Chem. Phys. 1970, 53, 1126-1130. [CrossRef]

22. Nemanich, R.J.; Solin, S.A. First-and second-order Raman scattering from finite-size crystals of graphite. Phys. Rev. B 1979, 20, 392. [CrossRef]

23. Lespade, P.; Al-Jishi, R.; Dresselhaus, M.S. Model for Raman scattering from incompletely graphitized carbons. Carbon 1982, 20, 427-431. [CrossRef]

24. Wada, N.; Gaczi, P.J.; Solin, S.A. “Diamond-like” 3-fold coordinated amorphous carbon. J. Non Cryst. Solids 1980, 35, 543-548. [CrossRef]

25. Dillon, R.O.; Woollam, J.A.; Katkanant, V. Use of Raman scattering to investigate disorder and crystallite formation in as-deposited and annealed carbon films. Phys. Rev. B 1984, 29, 3482. [CrossRef]

26. Yoshikawa, M.; Nagai, N.; Matsuki, M.; Fukuda, H.; Katagiri, G.; Ishida, H.; Ishitani, A.; Nagai, I. Raman scattering from sp 2 carbon clusters. Phys. Rev. B 1992, 46, 7169. [CrossRef] [PubMed]

27. Wagner, J.; Ramsteiner, M.; Wild, C.; Koidl, P. Resonant Raman scattering of amorphous carbon and polycrystalline diamond films. Phys. Rev. B 1989, 40, 1817. [CrossRef]

28. Schwan, J.; Ulrich, S.; Batori, V.; Ehrhardt, H.; Silva, S.R.P. Raman spectroscopy on amorphous carbon films. J. Appl. Phys. 1996, 80, 440-447. [CrossRef]

29. Wojcik, P.M.; Bakharev, P.V.; Corti, G.; McIlroy, D.N. Nucleation, evolution, and growth dynamics of amorphous silica nanosprings. Mater. Res. Express 2017, 4, 015004. [CrossRef]

30. Wang, L.; Major, D.; Paga, P.; Zhang, D.; Norton, M.G.; McIlroy, D.N. High yield synthesis and lithography of silica-based nanospring mats. Nanotechnology 2006, 17, S298-S303. [CrossRef]

31. Xie, Y.; McAllister, S.D.; Hyde, S.A.; Sundararajan, J.P.; FouetioKengne, B.A.; McIlroy, D.N.; Cheng, I.F. Sulfur as an important co-factor in the formation of multilayer graphene in the thermolyzed asphalt reaction. J. Mater. Chem. 2012, 22, 5723. [CrossRef]

32. Ferrari, A.C.; Robertson, J. Interpretation of Raman spectra of disordered and amorphous carbon. Phys. Rev. B 2000, 61, 14095. [CrossRef]

33. Gruen, D.M. Nanocrystalline diamond films. Annu. Rev. Mater. Sci. 1999, 29, 211-259. [CrossRef]

34. Zhou, D.; Gruen, D.M.; Qin, L.C.; McCauley, T.G.; Krauss, A.R. Control of diamond film microstructure by Ar additions to $\mathrm{CH}_{4} / \mathrm{H}_{2}$ microwave plasmas. J. Appl. Phys. 1998, 84, 1981-1989. [CrossRef]

35. Nemanich, R.J.; Glass, J.T.; Lucovsky, G.; Shroder, R.E. Raman scattering characterization of carbon bonding in diamond and diamondlike thin films. J. Vac. Sci. Technol. Vac. Surf. Film. 1988, 6, 1783-1787. [CrossRef]

36. Shroder, R.E.; Nemanich, R.J.; Glass, J.T. Analysis of the composite structures in diamond thin films by Raman spectroscopy. Phys. Rev. B 1990, 41, 3738. [CrossRef]

37. Ferrari, A.C.; Robertson, J. Origin of the $1150-\mathrm{cm}^{-1}$ Raman mode in nanocrystalline diamond. Phys. Rev. $B$ 2001, 63. [CrossRef]

38. Ferrari, A.C.; Basko, D.M. Raman spectroscopy as a versatile tool for studying the properties of graphene. Nat. Nanotechnol. 2013, 8, 235-246. [CrossRef]

39. Martins Ferreira, E.H.; Moutinho, M.V.O.; Stavale, F.; Lucchese, M.M.; Capaz, R.B.; Achete, C.A.; Jorio, A. Evolution of the Raman spectra from single-, few-, and many-layer graphene with increasing disorder. Phys. Rev. B 2010, 82. [CrossRef] 
40. Pócsik, I.; Hundhausen, M.; Koós, M.; Ley, L. Origin of the D peak in the Raman spectrum of microcrystalline graphite. J. Non-Cryst. Solids 1998, 227, 1083-1086. [CrossRef]

41. Ferrari, A.C.; Robertson, J. Resonant Raman spectroscopy of disordered, amorphous, and diamondlike carbon. Phys. Rev. B 2001, 64. [CrossRef]

42. Matthews, M.J.; Pimenta, M.A.; Dresselhaus, G.; Dresselhaus, M.S.; Endo, M. Origin of dispersive effects of the Raman D band in carbon materials. Phys. Rev. B 1999, 59, R6585. [CrossRef]

43. Inagaki, M. Discussion of the formation of nanometric texture in spherical carbon bodies. Carbon 1997, 35, 711-713. [CrossRef]

44. Serp, P.; Feurer, R.; Kalck, P.; Kihn, Y.; Faria, J.L.; Figueiredo, J.L. A chemical vapour deposition process for the production of carbon nanospheres. Carbon 2001, 39, 621-626. [CrossRef]

45. Kang, Z.C.; Wang, Z.L. On accretion of nanosize carbon spheres. J. Phys. Chem. 1996, 100, 5163-5165. [CrossRef]

46. Kang, Z.C.; Wang, Z.L. Chemical activities of graphitic carbon spheres. J. Mol. Catal. Chem. 1997, 118, 215-222. [CrossRef]

47. Qian, H.; Han, F.; Zhang, B.; Guo, Y.; Yue, J.; Peng, B. Non-catalytic CVD preparation of carbon spheres with a specific size. Carbon 2004, 42, 761-766. [CrossRef]

48. Jin, Y.Z.; Gao, C.; Hsu, W.K.; Zhu, Y.; Huczko, A.; Bystrzejewski, M.; Roe, M.; Lee, C.Y.; Acquah, S.; Kroto, H.; et al. Large-scale synthesis and characterization of carbon spheres prepared by direct pyrolysis of hydrocarbons. Carbon 2005, 43, 1944-1953. [CrossRef]

49. Nieto-Márquez, A.; Valverde, J.L.; Keane, M.A. Selective low temperature synthesis of carbon nanospheres via the catalytic decomposition of trichloroethylene. Appl. Catal. Gen. 2009, 352, 159-170. [CrossRef]

50. Zhang, Y.; Yang, W.; Luo, R.; Shang, H. Preparation of carbon nanospheres by non-catalytic chemical vapor deposition and their formation mechanism. New Carbon Mater. 2016, 31, 467-474. [CrossRef]

51. Venugopal, A.; Pirkle, A.; Wallace, R.M.; Colombo, L.; Vogel, E.M.; Secula, E.M.; Seiler, D.G.; Khosla, R.P.; Herr, D.; Michael Garner, C.; et al. Contact Resistance Studies of Metal on HOPG and Graphene Stacks; AIP: College Park, MD, USA, 2009; pp. 324-327.

52. Anteroinen, J.; Kim, W.; Stadius, K.; Riikonen, J.; Lipsanen, H.; Ryynanen, J. Extraction of graphene-titanium contact resistances using transfer length measurement and a curve-fit method. World Acad. Sci. Eng. Technol. 2012, 6, 8-25.

53. Zeiger, M.; Jäckel, N.; Mochalin, V.N.; Presser, V. Review: Carbon onions for electrochemical energy storage. J. Mater. Chem. A 2016, 4, 3172-3196. [CrossRef]

54. Liu, M. Coating Technology of Nuclear Fuel Kernels: A Multiscale View. In Modern Surface Engineering Treatments; Aliofkhazraei, M., Ed.; InTech Open: London, UK, 2013; ISBN 978-953-51-1149-8.

55. Pawlyta, M.; Hercman, H. Transmission electron microscopy (TEM) as a tool for identification of combustion products: Application to black layers in speleothems. Ann. Soc. Geol. Pol. 2016, 86, 237-248. [CrossRef]

56. Buseck, P.R.; Adachi, K.; Gelencsér, A.; Tompa, É.; Pósfai, M. Ns-Soot: A Material-Based Term for Strongly Light-Absorbing Carbonaceous Particles. Aerosol Sci. Technol. 2014, 48, 777-788. [CrossRef]

(C) 2019 by the authors. Licensee MDPI, Basel, Switzerland. This article is an open access article distributed under the terms and conditions of the Creative Commons Attribution (CC BY) license (http://creativecommons.org/licenses/by/4.0/). 